\title{
Factors associated with smoking cessation in patients with coronary heart disease: a cohort analysis of the German subset of EuroAspire IV survey
}

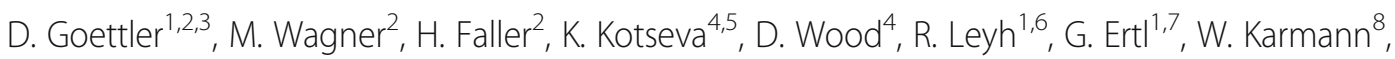
P. U. Heuschmann ${ }^{1,2,9}$, S. Störk ${ }^{1,7^{*}}$ and on behalf of the German EUROASPIRE IV collaborators

\begin{abstract}
Background: Tobacco smoking is one of the most important risk factors of coronary heart disease (CHD). Hence, smoking cessation is considered pivotal in the prevention of CHD. The current study aimed to evaluate smoking cessation patterns and determine factors associated with smoking cessation in patients with established CHD.

Methods: The fourth European Survey of Cardiovascular Disease Prevention and Diabetes investigated quality of CHD care in 24 countries across Europe in 2012/13. In the German subset, smoking cessation patterns and clinical characteristics were repetitively assessed a) during index event due to CHD by medical record abstraction, b) as part of a face-to-face interview 6 to 36 months after the index event (i.e. baseline visit), and c) by telephone-based follow-up interview two years after the baseline visit. Logistic regression analysis was performed to search for factors determining smoking status at the time of the telephone interview.

Results: Out of 469 participants available for follow-up, 104 (22.2\%) had been classified as current smokers at the index event. Of those, 65 patients (62.5\%) had quit smoking at the time of the telephone interview, i.e., after a median observation period of 3.5 years (quartiles 3.0, 4.1). Depressed mood at baseline visit and higher education level were less prevalent amongst quitters vs non-quitters ( $17.2 \%$ vs $35.9 \%, p=0.03$ and $15.4 \%$ vs $33.3 \%, p=0.03)$, cardiac rehabilitation programs were more frequently attended by quitters ( $83.1 \%$ vs $48.7 \%, p<0.001)$, and there was a trend for a higher prevalence of diabetes at baseline visit in quitters (37.5\% vs $20.5 \%, p=0.07)$. In the final multivariable model, cardiac rehabilitation was associated with smoking cessation (OR 5.19; 95\%Cl 1.87 to $14.46 ; p=0.002$ ).

Discussion: Attending a cardiac rehabilitation program after a cardiovascular event was associated with smoking cessation supporting its use as a platform for smoking cessation counseling and relapse prevention.
\end{abstract}

Keywords: Tobacco smoking, Smoking cessation, Coronary heart disease, Secondary prevention, Cardiac rehabilitation

\footnotetext{
* Correspondence: Stoerk S@ukw.de

${ }^{1}$ Comprehensive Heart Failure Center, University and University Hospital Würzburg, Am Schwarzenberg 15, Haus A15, D-97078 Würzburg, Germany

${ }^{7}$ Department of Internal Medicine I, University and University Hospital of Würzburg, Würzburg, Germany
}

Full list of author information is available at the end of the article

C C The Author(s). 2020 Open Access This article is licensed under a Creative Commons Attribution 4.0 International License, which permits use, sharing, adaptation, distribution and reproduction in any medium or format, as long as you give appropriate credit to the original author(s) and the source, provide a link to the Creative Commons licence, and indicate if changes were made. The images or other third party material in this article are included in the article's Creative Commons licence, unless indicated otherwise in a credit line to the material. If material is not included in the article's Creative Commons licence and your intended use is not permitted by statutory regulation or exceeds the permitted use, you will need to obtain permission directly from the copyright holder. To view a copy of this licence, visit http://creativecommons.org/licenses/by/4.0/. The Creative Commons Public Domain Dedication waiver (http://creativecommons.org/publicdomain/zero/1.0/) applies to the data made available in this article, unless otherwise stated in a credit line to the data. 


\section{Background}

Smoking remains a leading risk factor for a variety of diseases and belongs to the most important causes of preventable death [1]. Coronary heart disease (CHD) was the leading single cause of death in the year 2015 [2]. Thirteen smokers need to quit to save one life by smoking cessation after myocardial infarction [3]. The risk of recurrent myocardial infarction is markedly decreased by smoking cessation compared to persistent smoking [4]. Hence, smoking cessation is a pivotal, guideline-supported recommendation in the setting of both primary and secondary prevention of CHD [5]. After an acute cardiac event, approximately half of prior smokers quit smoking [6]. Successful cessation is predominantly driven by discharge recommendations for cardiac rehabilitation, absence of depressed mood and coronary surgery during index hospitalization $[7,8]$.

For the entire dataset of the fourth European Action on Secondary and Primary Prevention by Intervention to Reduce Events (EuroAspire) IV [9], rates of current smoking at the CHD index event were reported for $16.0 \%$, and persistent smoking 6 to 36 months later for $48.6 \%$. The present study aimed to expand this observation period for the German subset enrolled in EuroAspire IV by another two years in order to study the sustainability of cessation patterns and identify factors associated with smoking cessation.

\section{Methods}

\section{Study population and design}

The fourth European Action on Secondary and Primary Prevention by Intervention to Reduce Events "EuroAspire IV" was a cross-sectional survey conducted at 78 centers in 24 European countries between May 2012 and April 2013 by the European Society of Cardiology. Detailed information on the EuroAspire IV study methodology has been provided previously [9]. Briefly, inclusion criteria, applicable to the index event, were: first or recurrent clinical diagnosis of elective or emergency coronary artery bypass graft (CABG), elective or emergency percutaneous coronary intervention (PCI), acute myocardial infarction (AMI) or acute myocardial ischemia without infarction (AMIsch; troponin negative), and age 18 to 79 years at the date of index event. For the German subset of EuroAspire IV, patients admitted to the University Hospital of Würzburg or the hospital Klinik Kitzinger Land were included. Eligible subjects were identified using appropriate search algorithms applied to the hospital information system and then invited to and examined at the study sites within 6 to 36 months after the CHD index event [10]. All subjects provided written informed consent prior to any study-related investigation. Trained research staff retrospectively extracted all relevant information applying to the index event of study participants from medical records. Further, study participants were invited to the study site for their baseline visit and underwent a personal interview, standardized questionnaires and laboratory analysis. Germany also participated in the EuroAspire IV follow-up initiative that asked for a prospective follow-up about two years after the baseline visit [11]. This follow-up information was collected via a standardized telephone-based interview (see supplemental files).

\section{Definitions}

Information on smoking status was missing for 59 participants in the medical record. To minimize drop-outs due to missing data, two variables from different time points were combined to define smoking status at index event: a) smoking status according to the medical record at index event, and b) current smoking one month prior to the index event as assessed retrospectively at the study baseline visit. Smoking status at baseline visit was confirmed by $\mathrm{CO}$ smokerlyser and the definition of smoking was "self-reported smoking and/or breath $\mathrm{CO}>10 \mathrm{ppm}$ ". Smoking status at the time of the CHD index event (from medical record) and at the follow-up (by telephone interview) was bases on the "self-reported" smoking only. At the baseline visit, study participants reported their highest level of education; for this analysis, high school completed, college/university completed or post graduate degree were defined as high educational level. The cardiac event leading to the index hospitalization was used for classification (i.e., CABG, PCI, AMI, or AMIsch). Diabetes was defined according to ESC 2013/ADA 2012 criteria by plasma glucose $\geq 7.0 \mathrm{mmol} / \mathrm{l}$ or plasma glucose $\geq 11.1 \mathrm{mmol} / \mathrm{l} 2 \mathrm{~h}$ after standardized glucose load [12]. Depressed mood was assessed using the German version of the Hospital Anxiety and Depression Scale (HADS) questionnaire at the baseline visit. Its sub-test on depression uses seven items addressing depressive symptoms on an ordinal scale. Since all items have values ranging 0 to 3 the test for depression has a maximum score of 21. Presence of depressed mood was defined as sum score of eight or more [13]. At the baseline visit all participants were asked if they had been advised to attend a cardiac rehabilitation program within three months of discharge following the index event. Subsequently, the frequency of participation was assessed. Cardiac rehabilitation was counted as "participation", if the participant had attended at least half of the recommended sessions. Data on the duration and type of the cardiac rehabilitation program (center-based vs home-based) were not systematically collected. In Germany, cardiac rehabilitation programs are usually center-based with a duration of three to four weeks. 


\section{Outcome measure and data analysis}

The primary endpoint of the current analysis was smoking status at the telephone-based follow-up interview amongst subjects classified as current smokers at the index event. Subsequently, the association between age, sex, educational level, coronary surgery at index event, diabetes, depressed mood and cardiac rehabilitation with smoking status at telephone-based follow-up interview was investigated. We compared smokers to non-smokers using statistical tests as described in the following. Continuous normally distributed variables are presented as mean (standard deviation) and analyzed by independent samples $t$-test. Nominal variables are presented as frequency (percentage) and analyzed by chi-squared test or Fisher's exact test. A multivariable binary logistic regression model was built to illustrate effect sizes. Results are presented as odds ratios (OR) with $95 \%$ confidence intervals $(95 \% \mathrm{CI})$ and $p$-values. Models were constructed block-wise: 1) sociodemographic variables (age, sex, educational level), 2) comorbidities (CABG at index event; diabetes or depressed mood at baseline visit), 3) participation in a cardiac rehabilitation program after the index event. Nagelkerke's $R^{2}$ values of respective models are presented to quantify goodness of fit. All analyses were performed using IBM SPSS Statistics, version 23.0 (IBM Corporation, NY, USA). Two-tailed $p$-values $<0.05$ were considered statistically significant.

\section{Results}

Between August 2012 and March 2013, a total of 1380 persons were invited to participate in the German EuroAspire IV survey and 536 (38.8\%) participated in the baseline visit. Baseline characteristics of the whole study population have been provided previously [14]. Of patients attending the baseline interview, 469 (87.5\%) participated in the telephone-based follow-up interview. 124 of 536 (23.1\%) patients were classified as current smokers at the index event. Of those, 104 (83.9\%) participated in the telephone-based follow-up interview, thus, contributing to primary endpoint analyses (Fig. 1). The median time between index event and baseline visit was
1.8 years (quartiles 1.3, 2.4). Time between baseline visit and telephone-based follow-up interview was 1.8 years (quartiles 1.7, 1.8). Thus, the median total observation time for the 104 participants was 3.5 years (quartiles 3.0, 4.1). As compared to smokers at index event participating in the telephone-based follow-up interview $(n=104)$ non-participating smokers $(n=20)$ were older, more often diabetic and more often smokers at the baseline visit (all $p<0.05$; see Supplemental table 1).

\section{Smoking cessation patterns}

As presented in Fig. 1, 65 of 104 (62.5\%) current smokers at index event had stopped smoking at telephone-based follow-up interview (median 3.5 years, see above). Of those, 63 (60.6\%) participants quitted smoking between index event and baseline visit, but 4 (3.8\%) subsequently relapsed until telephone-based follow-up interview. Late cessation was reported by 6 (5.8\%) patients at telephone-based follow-up interview who were current smokers at index event and baseline visit. At the baseline visit $61(64.2 \%)$ current smokers at index event reported to have received verbal advice to stop smoking following hospital discharge and 25 (26.3\%) had been offered written information material. Recommendations to use pharmacological support (e.g. nicotine replacement therapy $16.8 \%$, bupropion $0 \%$ or vareniclin $0 \%$ ) were rarely reported. $26(68.4 \%)$ current smokers at the baseline visit reported reduced smoking intensity since the index event but had not managed quitting. 19 of 39 (48.7\%) persistent smokers at the telephone-based followup interview reported on any environmental tobacco smoke exposition (ETS) compared to 9 of 65 (13.8\%) successful quitters. ETS was associated with reduced rates of smoking cessation (OR 0.16, 95\%CI 0.06-0.42; $p<0.001$; adjusted for age and sex). In the subgroup of smokers at index event not participating in a cardiac rehabilitation program but reporting ETS at baseline visit $(n=12)$, the rate of persistent smoking was $91.7 \%$.

Seventy-six of 104 (73.1\%) current smokers at index event reported having been advised to attend a cardiac rehabilitation program within three months of discharge

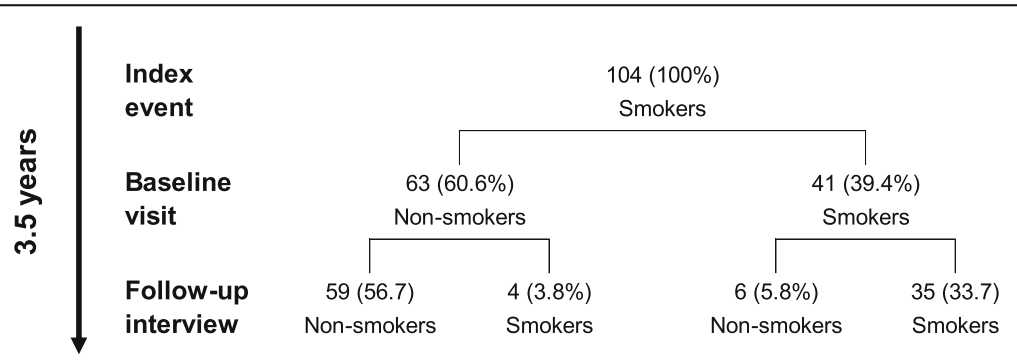

Fig. 1 Frequency of smoking cessation in smokers with CHD. Index event occurred 6-36 months prior to baseline visit, and follow-up interview occurred about 2 years after baseline visit; median observation time between index event and telephone-based follow-up interview was 3.5 years (quartiles 3.0, 4.1) 
(successful quitters vs persistent smokers at follow-up interview, $84.6 \%$ vs $53.8 \%, p=0.001)$. Of those, 73 (96.1\%) attended more than half of the recommended sessions (successful quitters vs persistent smokers at follow-up interview, 98.2\% vs 90.5\%, $p=0.12$ ). Among participants of such a program, 67 (91.8\%) received written educational materials, 69 (94.5\%) took part in supervised exercise programs, $71(97.3 \%)$ in health promotion workshops, and $62(84.9 \%)$ in stress modification and relaxation interventions. Fourteen subjects (19.2\%) participated in dedicated smoking cessation programs. Smokers reporting a quitting attempt prior to the index event were more likely to attend a cardiac rehabilitation program than smokers never reporting a quitting attempt $(76.5 \%$ vs $58.3 \%$; $p=0.05)$.

Comparison of persistent smokers and successful quitters The group of current smokers at index event was approximately 60 years old and predominantly male. Neither age, nor sex nor coronary surgery during index event showed a statistically significant association with subsequent smoking status, whereas a high educational level was associated with persistent smoking in univariable analysis (Table 1). Smoking status at index event was not associated with high educational level (smokers vs non-smokers at index event, $22.1 \%$ vs $21.1 \%, p=$ 0.82 ). Present diabetes showed a non-significant trend towards higher quitting rates, whereas absence of depressed mood and participation in a cardiac rehabilitation program were associated with smoking cessation in univariable analysis. A block-wise multivariable logistic regression model was built to search for factors determining smoking status at the telephone-based follow-up interview (Table 2). In the age-adjusted model (block one), higher educational level was associated with lower rates of smoking cessation. Extending the model to comorbidities (block two), presence of depressed mood was associated with lower rates of smoking cessation. Finally (block three), the strong influence of participation in a cardiac rehabilitation program was maintained the only significant factor associated with smoking cessation in patients with established CHD who were smoking at the time of index event (OR 5.19, 95\%CI 1.87-14.46; $p=$ 0.002). Goodness of fit (Nagelkerke's $R^{2}$ ) increased accordingly when adding explanatory variables although the explained variance remained small: 6.7, 16.6, $28.4 \%$ in blocks one, two and three, respectively. Additional variables potentially further elucidating the acuity of the index event (i.e., emergency admission and AMI) were not associated with smoking cessation (see Supplemental Table 2 and Supplemental Table 3).

\section{Discussion}

About one third of study participants were current smokers at the time of the index event. After a median observation period of 3.5 years, more than $60 \%$ successfully quitted smoking. Age, sex, and coronary surgery at index event were not associated with smoking cessation in this cohort. Lower educational level and absence of depression/depressed mood showed univariate associations with smoking cessation that were lost after multivariable adjustment. There, only attendance of a cardiac rehabilitation program was associated with successful smoking cessation.

Comparable studies such as the entire EuroAspire IV dataset [9], PREMIER [8], OASIS [4], and Olmsted

Table 1 Current smokers at index event* $(n=104)$ stratified by their smoking status reported median 3.5 years later

\begin{tabular}{|c|c|c|c|c|}
\hline & Total & Non-smokers at follow-up interview & Smokers at follow-up interview & \\
\hline & $\mathbf{N}=104$ & $\boldsymbol{N}=65(62.5 \%)$ & $\boldsymbol{N}=39(37.5 \%)$ & $\boldsymbol{P}$-value \\
\hline \multicolumn{5}{|l|}{ Demography } \\
\hline Age at index event, years & $59.1 \pm 9.0$ & $59.5 \pm 9.0$ & $58.5 \pm 9.1$ & 0.61 \\
\hline Female sex & $16(15.4)$ & $11(16.9)$ & $5(12.8)$ & 0.58 \\
\hline High educational level ${ }^{\#}$ & $23(22.1)$ & $10(15.4)$ & $13(33.3)$ & 0.03 \\
\hline \multicolumn{5}{|l|}{ Comorbidities } \\
\hline Type of index event: CABG & $14(13.5)$ & $10(15.4)$ & $4(10.3)$ & 0.46 \\
\hline Diabetes (baseline) ${ }^{a}$ & $32(31.1)$ & $24(37.5)$ & $8(20.5)$ & 0.07 \\
\hline Depressed mood (baseline) ${ }^{b}$ & $25(24.3)$ & $11(17.2)$ & $14(35.9)$ & 0.03 \\
\hline \multicolumn{5}{|l|}{ Intervention } \\
\hline Cardiac rehabilitation program after index event & $73(70.2)$ & $54(83.1)$ & $19(48.7)$ & $<0.001$ \\
\hline
\end{tabular}

Data are $\mathrm{n}$ (percent) or mean \pm SD and $\mathrm{p}$-values by asymptotic Pearson's Chi-Squared test or independent sample t-test, as appropriate $C A B G$ coronary artery bypass graft

*Index event occurred 6-36 months prior to baseline visit, and telephone-based follow-up interview occurred about 2 years after baseline visit; median observation time between index event and telephone-based follow-up interview was 3.5 years

\#High school completed, college/university completed, postgraduate degree

${ }^{\text {a }}$ Data missing for 1 participant

${ }^{b}$ Data missing for 1 participant 
Table 2 Factors associated with smoking cessation (block-wise multivariable logistic regression)

\begin{tabular}{|c|c|c|c|c|c|c|}
\hline \multirow{3}{*}{ Nagelkerke's R squared } & \multicolumn{2}{|l|}{ Block 1} & \multicolumn{2}{|l|}{ Block 2} & \multicolumn{2}{|l|}{ Block 3} \\
\hline & \multicolumn{2}{|l|}{0.067} & \multicolumn{2}{|l|}{0.165} & \multicolumn{2}{|l|}{0.284} \\
\hline & OR $(95 \% \mathrm{Cl})$ & $\mathrm{P}$ & OR $(95 \% \mathrm{Cl})$ & $P$ & OR $(95 \% \mathrm{Cl})$ & $\mathrm{P}$ \\
\hline \multicolumn{7}{|l|}{ Demography } \\
\hline Age at index event* & $1.02(0.97-1.07)$ & 0.40 & $1.01(0.96-1.06)$ & 0.66 & $1.03(0.97-1.08)$ & 0.36 \\
\hline Female sex & $1.05(0.32-3.44)$ & 0.94 & $1.09(0.31-3.89)$ & 0.89 & $1.28(0.34-4.77)$ & 0.71 \\
\hline High educational level" & $0.34(0.13-0.91)$ & 0.03 & $0.37(0.13-1.03)$ & 0.06 & $0.39(0.13-1.17)$ & 0.09 \\
\hline \multicolumn{7}{|l|}{ Comorbidities } \\
\hline No $C A B G$ vs $C A B G$ & & & $1.12(0.28-4.52)$ & 0.87 & $0.63(0.15-2.68)$ & 0.53 \\
\hline Diabetes (baseline) ${ }^{\mathrm{a}}$ & & & $2.53(0.93-6.86)$ & 0.07 & $2.56(0.89-7.34)$ & 0.08 \\
\hline Depressed mood (baseline) $)^{b}$ & & & $0.32(0.12-0.87)$ & 0.03 & $0.37(0.13-1.08)$ & 0.07 \\
\hline \multicolumn{7}{|l|}{ Intervention } \\
\hline Rehabilitation program & & & & & $5.19(1.87-14.46)$ & 0.002 \\
\hline
\end{tabular}

County [15] reported smoking frequencies at an index event of $15-25 \%$, and subsequent smoking cessation rates of about $50-65 \%$, i.e. comparable to our findings. However, our analysis had the longest duration of follow-up. For the entire EuroAspire IV dataset one follow-up assessment of smoking status was done 6 to 36 months after the CHD index event (median 1.35 years; quartiles $0.95,1.93$ ); in PREMIER one assessment was done 6 month after AMI; the OASIS trial included one assessment 30 days and another 6 month after the diagnosis of unstable angina or AMI without ST-segment elevation; and Olmsted County reported quitting rates 6 month and 12 month after PCI. In our analysis smoking status was assessed at baseline visit 6 to 36 months after the CHD index event and again at telephone-based follow-up interview median 3.5 years (quartiles 3.0, 4.1) after the index event. Smoking rates at hospital admission and subsequent cessation rates after discharge apparently stagnated in Europe in the past decade, whereas smoking rates in patients aged below 50 years, especially in women, increased $[6,16]$. A recent Cochrane review reported evidence of reduced admission rates for acute coronary syndrome and reduced mortality from smoking-related illnesses due to the implementation of World health organization recommended anti-smoking legislation initiatives $[17,18]$. Results from Germany concur with these developments, but emphasize that reduced hospital admission rates for ST-elevation AMI in the period after implementing anti-smoking legislation were predominantly observed in non-smokers [19]. Reduced exposure to ETS by public smoking bans may reduce cardiovascular risk for non-smokers without measurably protecting smokers due to the prevailing effect of active smoking [19].
In our study, evidence-based treatment options for smoking cessation were rarely applied: $64.2 \%$ received verbal advice, $26.3 \%$ written information material and only $16.8 \%$ were advised to use nicotine replacement therapy, respectively. To be as effective as possible, smoking cessation schemes may include the comprehensive medical advice, behavioral aspects, communityoriented approaches and appropriate pharmacotherapeutic support [20, 21]. Any type of nicotine replacement therapy compared to control increases the chance of successful quitting by $50-70 \%$ according to a systematic Cochrane review [22]. Nevertheless, throughout Europe, smoking cessation counselling and medication remains heavily underused in clinical practice [9, 23]. Half of German general practitioners reported low activity in smoking cessation promotion [24]. Hence, the barriers to smoking cessation need to be addressed comprehensively. Exposure to ETS was more common in persistent smokers than successful quitters in this cohort, especially at home. Continuous exposure to tobacco smoke may impede successful cessation and foster relapse.

Higher levels and longer periods of education were shown to be associated with non-smoking, improvements in cardiovascular risk factor control, smoking cessation in $\mathrm{CHD}$ patients and smoking cessation in healthy youth and adults smokers [25-28]. Surprisingly, in this cohort of 104 pre-CHD-event smokers, there was a univariate association of higher educational level with persistent smoking, that lost significance in the multivariable model. By contrast, smoking status at index event was not associated with higher educational level. Higher educational level was defined by high school completed, college/university completed or postgraduate degree. Supporting this 
finding, young Chinese male adult smokers with higher levels of education, defined by $\geq$ senior college or university, were more inclined to smoke, despite a better knowledge on tobacco related health hazards [29]. The definition of higher education is subject to variation: more than primary school [26], more than high school [27] or three ordinal categories such as primary, secondary and tertiary education $[25,28]$ are used to define educational level in this context. As 103 of 104 German pre-event smokers had more than primary school leaving qualification, the observed association vanished when higher education was defined by more than primary school. Nevertheless, increased rates of persistent smoking in the subgroup of pre-event smokers with very high school leaving qualification are a reason for concern.

In our study, there was an association of depressed mood with lower quitting rates in patients with $\mathrm{CHD}$ in univariable analysis that was lost after multivariable adjustment. Comparable studies with higher sample size had reported a significant association [8]. Both smoking and depression/depressed mood were shown to negatively impact on cardiovascular mortality, morbidity and quality of life [30]. The relationship between depression/ depressed mood and smoking in CHD includes a bidirectional influence, as well as genetic determination [31]. Although it is yet unknown whether routine screening for psychosocial risk factors may reduce future cardiac events, the negative influence of depression/depressed mood on both smoking cessation and CHD is commonly acknowledged. According to current guidelines physicians were encouraged to screen smokers with CHD for comorbid depression/depressed mood. It is plausible that successful targeting depression may raise chances of successful smoking cessation [5].

The rates of participation in a cardiac rehabilitation program in the German part of EuroAspire IV were higher than average, especially for smokers at index event $[9,32$, 33]. Attending a cardiac rehabilitation program was shown to improve successful cessation and lower mortality rates in systematic reviews and meta-analysis of randomized controlled trials [5, 34-37]. According to a recent analysis based on a Cochrane review, $58 \%$ of the beneficial effects of cardiac rehabilitation programs were attributable to changes in cardiovascular risk factors (i.e., smoking, lipids, blood pressure) and $24 \%$ of the total mortality risk reduction might be accountable to reduced smoking [38]. However, the analysis of the entire EuroAspire IV data set showed no association of smoking cessation with survival in the telephone-based follow-up interview period [11]. Though pre-event smokers were less likely to participate, the entire EuroAspire IV data set showed a positive correlation of participating in a cardiac rehabilitation program and quitting smoking at baseline visit 6 to 36 months after the CHD index event $[26,39]$. Supporting this findings, we observed a strong correlation of participating in a cardiac rehabilitation program and quitting at telephonebased follow-up interview median 3.5 years after the CHD index event. The effect size found in the present study relating participation in a cardiac rehabilitation program and successful smoking cessation appears high compared to published literature $[8,15]$. Nevertheless, these findings support the importance of cardiac rehabilitation programs in secondary prevention of $\mathrm{CHD}$, thus encouraging physicians to more actively advocate this strategy.

\section{Limitations and strengths}

The EuroAspire surveys rely on defined geographical areas [9]. Hence, patient characteristics and treatment quality may have differed from CHD populations in other regions in Germany. Furthermore, participation rate in the baseline interview was low, which is in accordance with the overall trend of declining response rates during the past decades [40]. The sample size was too small to verify or disprove the non-significant associations of education and depressed mood with smoking cessation or enrich the multivariable model with additional variables such as retrospective characteristics of smoking history, comorbidities or cessation efforts. The overall explanatory power of the multivariable model was low due the small sample size. This reflects the complexity of predicting behavioral change adequately. Smoking status was assessed by self-report by accepted methods (reported sensitivity $87.5 \%$, specificity $89.2 \%$ [41];). The duration and intensity of smoking (i.e., pack years) was not documented in the medical records at index event obtained retrospectively and could not reliably be recorded during the interview due to recall bias.

Strengths of the current analysis include the use of standardized comparable methods ranging from medical record data extraction forms, questionnaires and centralized laboratory assessments. The personal interviews provided detailed and complete risk factor recording, which comparable studies based on medical records alone often lacked. A small but very high-risk sample was studied in matters of the modifiable risk factor tobacco smoking.

\section{Conclusions}

Smoking rates at a cardiac event, as well as, persistent smoking rates were high in this cohort. Evidencebased options supporting smoking cessation such as comprehensive medical counseling and nicotine replacement therapy were underused. Referral to a cardiac rehabilitation program was strongly associated with smoking cessation. Referral rates were higher than average in the subgroup of smokers, but 
coverage remained incomplete. Cardiologists and general practitioners in hospitals and primary care facilities should be motivated to enhance non-pharmacological risk factor control, especially smoking cessation counselling and referral to a cardiac rehabilitation program as important means to improve the success of secondary prevention efforts.

\section{Supplementary information}

Supplementary information accompanies this paper at https://doi.org/10. 1186/s12872-020-01429-w.

Additional file 1: Supplemental Table 1. Current smokers at index event* $(n=124)$ stratified by their participation at telephone-based follow-up interview. Supplemental Table 2. Clinical data of current smokers at index event* $(n=104)$ stratified by their smoking status reported 3.5 years later. Supplemental Table 3. Factors associated with smoking cessation (block-wise multivariable logistic regression).

Additional file 2. EuroAspire IV Germany I Follow-up interview I Questionnaire.

\section{Abbreviations}

CHD: Coronary heart disease; EuroAspire IV: European action on secondary and primary prevention by intervention to reduce events; CABG: Coronary artery bypass graft; PCI: Percutaneous coronary intervention; AMI: Acute myocardial infarction; AMlsch: Acute myocardial ischemia without infarction; HADS: Hospital anxiety and depression scale; ETS: Environmental tobacco smoke

\section{Acknowledgments}

We thank the study participants of the German EuroAspire IV survey and the participating clinics University Hospital Würzburg and Klinik Kitzinger Land. We express our gratitude to all supporting doctoral students (Kim Nolte, Martin Schich, Valerie Wahl) and research staff (Margret Breunig, Kerstin Eichstädt, Andre Gerhardt, Timo Ludwig, Yvonne Memmel, Anika Quilitzsch, Dominik Schmitt, Theresa Tiffe). Thank you very much Cornelia Fiessler for verifying the statistical analysis.

\section{Authors' contributions}

All authors have participated in the work and have reviewed and agree with the content of this article. Study concept and design: DG, MW, HF, KK, DW, RL, GE, WK, PUH, StS. Acquisition, analysis or interpretation of data: DG, MW, HF, PUH, StS. Drafting of the manuscript: DG, HF, PUH, StS. Critical revision of the manuscript: DG, MW, HF, KK, DW, RL, GE, WK, PUH, StS. Funding: PUH, StS. Study supervision: PUH, StS. All authors attest they meet the ICMJE criteria for authorship. The author(s) read and approved the final manuscript.

\section{Funding}

The EUROASPIRE IV survey was carried out under the auspices of the European Society of Cardiology, EURObservational Research Programme, and was supported by grants to the ESC from Amgen (EUROPE) GmbH, AstraZeneca AB, BMS/AstraZeneca, F. Hoffmann La Roche, GlaxoSmithKline PLC, and Merck \& Co. The researchers were independent of the funders who had no influence on study design, data collection, data analysis, data interpretation, decision to publish, or writing the manuscript. Data collection at the German EUROASPIRE IV study center was supported by the German Ministry of Education and Research (BMBF) within the Comprehensive Heart Failure Center Würzburg (BMBF $01 E O 1004$ and 01EO1504). DG received a scholarship from the Graduate School of Life Sciences (GSLS) of the University of Würzburg from 04/2014-03/2015.

\section{Availability of data and materials}

All data that support the findings of this study are included in this published article. The datasets used and/or analysed during the current study are available from the corresponding author on reasonable request.

\section{Ethics approval and consent to participate}

The study conforms with the Declaration of Helsinki. The Ethics Committee of the Medical Faculty of the University of Würzburg approved the study (EK Votum 58/12). Written informed consent was obtained from each participant. Recruitment strategy, data acquisition, and data storage was authorized by the data protection officer at the University of Würzburg.

\section{Consent for publication}

Not applicable.

\section{Competing interests}

PUH reports grants from German Ministry of Research and Education, European Union, German Research Foundation, Charité-Universitätsmedizin Berlin, Berlin Chamber of Physicians, German Parkinson Society, University Hospital Würzburg, Robert-Koch-Institute, German Heart Foundation, Federal Joint Committee (G-BA) within the Innovationfond, University Hospital Heidelberg (within RASUNOA-prime; supported by an unrestricted research grant to the University Hospital Heidelberg from Bayer, BMS, BoehringerIngelheim, Daiichi Sankyo), Charité-Universitätsmedizin Berlin (within Mondafis; supported by an unrestricted research grant to the Charite from Bayer), University Göttingen (within FIND-AF randomized; supported by an unrestricted research grant to the University Göttingen from BoehringerIngelheim), outside the submitted work. HF reports grants from German Ministry of Research and Education, German Ministry of Health, Bavarian State Ministry of the Environment and Public Health, German Research Foundation, Federal Joint Committee (G-BA) within the Innovationsfond, German Statutory Pension Insurance, German Statutory Accident Insurance, Network of Rehabilitation Research in Bavaria, German Cancer Aid, outside the submitted work. KK and DW had grant support from the European Society of Cardiology. KK received travel grants from Roche and Boehringer Ingelheim, and DW reports honoraria for invited lectures or advisory boards: AstraZeneca, Merck Sharp and Dohme, Kowa Pharmaceuticals, Menarini, and Zentiva; and consultancy: Merck Sharp and Dohme. GE reports research grants from the German Ministry of Education and Research (BMBF), Lundbeck non-financial support, Bayer grants, and Novartis grants and personal fees. RL received speaker honoraria from Edwards Lifesciences and Stryker. StS reports research grants from the German Ministry of Education and Research, European Union, and University Hospital Würzburg; participation in Data Safety Monitoring and Event Adjudication Boards in trials sponsored by Roche and Medtronic; principal investigator in trials sponsored by Bayer, Boehringer, Novartis; speaker honoraria by and advisory board activities for AstraZeneca, Bayer, Boehringer, Novartis, Servier, and Pfizer. DG included elements of this publication in his doctoral thesis. MW and WK have nothing to disclose.

\section{Author details}

${ }^{1}$ Comprehensive Heart Failure Center, University and University Hospital Würzburg, Am Schwarzenberg 15, Haus A15, D-97078 Würzburg, Germany. ${ }^{2}$ Institute for Clinical Epidemiology and Biometry, University of Würzburg, Würzburg, Germany. ${ }^{3}$ Department of Pediatrics, University Hospital of Würzburg, Würzburg, Germany. ${ }^{4}$ National Institute for Prevention and Cardiovascular Health, National University of Ireland, Galway, Ireland. ${ }^{5}$ Imperial College Healthcare NHS Trust, London, UK. ${ }^{6}$ Department of Thoracic and Cardiovascular Surgery, University Hospital Würzburg, Würzburg, Germany. ${ }^{7}$ Department of Internal Medicine I, University and University Hospital of Würzburg, Würzburg, Germany. ${ }^{8}$ Department of Medicine, Klinik Kitzinger Land, Kitzingen, Germany. ${ }^{9} \mathrm{Clinical}$ Trial Center, University Hospital of Würzburg, Würzburg, Germany.

Received: 6 February 2020 Accepted: 12 March 2020

Published online: 30 March 2020

\section{References}

1. G. B. D. Risk Factors Collaborators, Forouzanfar MH, Alexander L, Anderson HR, Bachman VF, Biryukov S, Brauer M, Burnett R, Casey D, Coates MM, et al. Global, regional, and national comparative risk assessment of 79 behavioural, environmental and occupational, and metabolic risks or clusters of risks in 188 countries, 1990-2013: a systematic analysis for the Global Burden of Disease Study 2013. Lancet. 2015;386(10010):2287-323. https://doi.org/10.1016/S0140-6736(15)00128-2.

2. Roth GA, Johnson C, Abajobir A, Abd-Allah F, Abera SF, Abyu G, Ahmed M, Aksut B, Alam T, Alam K, et al. Global, regional, and National Burden of 
cardiovascular diseases for 10 causes, 1990 to 2015. J Am Coll Cardiol. 2017; 70(1):1-25. https://doi.org/10.1016/i.jacc.2017.04.052.

3. Wilson K, Gibson N, Willan A, Cook D. Effect of smoking cessation on mortality after myocardial infarction: meta-analysis of cohort studies. Arch Intern Med. 2000;160(7):939-44. https://doi.org/10.1001/archinte.160.7.939.

4. Chow CK, Jolly S, Rao-Melacini P, Fox KA, Anand SS, Yusuf S. Association of diet, exercise, and smoking modification with risk of early cardiovascular events after acute coronary syndromes. Circulation. 2010;121(6):750-8. https://doi.org/10.1161/CIRCULATIONAHA.109.891523.

5. Piepoli MF, Hoes AW, Agewall S, Albus C, Brotons C, Catapano AL, Cooney MT, Corra U, Cosyns B, Deaton C, et al. 2016 European Guidelines on cardiovascular disease prevention in clinical practice: The Sixth Joint Task Force of the European Society of Cardiology and Other Societies on Cardiovascular Disease Prevention in Clinical Practice (constituted by representatives of 10 societies and by invited experts) Developed with the special contribution of the European Association for Cardiovascular Prevention \& Rehabilitation (EACPR). Eur Heart J. 2016;37(29):2315-81. https://doi.org/10.1093/eurheartj/ehw106.

6. Kotseva K, De Bacquer D, Jennings C, Gyberg V, De Backer G, Ryden L, Amouyel P, Bruthans J, Cifkova R, Deckers JW, et al. Time trends in lifestyle, risk factor control, and use of evidence-based medications in patients with coronary heart disease in Europe: results from 3 EUROASPIRE surveys, 1999-2013. Glob Heart. 2017;12(4):315-22 e313. https://doi.org/10.1016/.j.gheart.2015.11.003.

7. Hammal F, Ezekowitz JA, Norris CM, Wild TC, Finegan BA, Approach investigators. Smoking status and survival: impact on mortality of continuing to smoke one year after the angiographic diagnosis of coronary artery disease, a prospective cohort study. BMC Cardiovasc Disord. 2014; 14(1):133. https://doi.org/10.1186/1471-2261-14-133.

8. Dawood N, Vaccarino V, Reid KJ, Spertus JA, Hamid N, Parashar S, Premier registry investigators. Predictors of smoking cessation after a myocardial infarction: the role of institutional smoking cessation programs in improving success. Arch Intern Med. 2008;168(18):1961-7. https://doi.org/10.1001/ archinte.168.18.1961.

9. Kotseva K, Wood D, De Bacquer D, De Backer G, Ryden L, Jennings C, Gyberg V, Amouyel P, Bruthans J, Castro Conde A, et al. EUROASPIRE IV: A European Society of Cardiology survey on the lifestyle, risk factor and therapeutic management of coronary patients from 24 European countries. Eur J Prev Cardiol. 2016;23(6):636-48. https://doi.org/10.1177/ 2047487315569401

10. Wagner M, Gelbrich G, Kircher J, Kotseva K, Wood D, Morbach C, Leyh R, Ertl G, Karmann W, Stork S, et al. Secondary prevention in younger vs. older coronary heart disease patients-insights from the German subset of the EUROASPIRE IV survey. Int J Behav Med. 2018;25(3):283-93. https://doi.org/ 10.1007/s12529-017-9691-y.

11. De Bacquer D, De Smedt D, Kotseva K, Jennings C, Wood D, Ryden L, Gyberg V, Shahim B, Amouyel P, Bruthans J, et al. Incidence of cardiovascular events in patients with stabilized coronary heart disease: the EUROASPIRE IV follow-up study. Eur J Epidemiol. 2019;34(3):247-58. https:// doi.org/10.1007/s10654-018-0454-0.

12. Authors/Task Force, Members, Ryden L, Grant PJ, Anker SD, Berne C, Cosentino F, Danchin N, Deaton C, Escaned J, Hammes HP, et al. ESC Guidelines on diabetes, pre-diabetes, and cardiovascular diseases developed in collaboration with the EASD: the Task Force on diabetes, pre-diabetes, and cardiovascular diseases of the European Society of Cardiology (ESC) and developed in collaboration with the European Association for the Study of Diabetes (EASD). Eur Heart J. 2013;34(39):3035-87. https://doi.org/ 10.1093/eurhearti/eht108.

13. Bjelland I, Dahl AA, Haug TT, Neckelmann D. The validity of the hospital anxiety and depression scale. An updated literature review. J Psychosom Res. 2002;52(2):69-77. https://doi.org/10.1016/s0022-3999(01)00296-3.

14. Tiffe T, Morbach C, Malsch C, Gelbrich G, Wahl V, Wagner M, Kotseva K, Wood D, Leyh R, Ertl G, et al. Physicians' lifestyle advice on primary and secondary cardiovascular disease prevention in Germany: a comparison between the STAAB cohort study and the German subset of EUROASPIRE IV. Eur J Prev Cardiol. 2019;2047487319838218. https://doi.org/10.1177/ 2047487319838218.

15. Sochor O, Lennon RJ, Rodriguez-Escudero JP, Bresnahan JF, Croghan I, Somers VK, Lopez-Jimenez F, Pack Q, Thomas RJ. Trends and predictors of smoking cessation after percutaneous coronary intervention (from Olmsted County, Minnesota, 1999 to 2010). Am J Cardiol. 2015;115(4):405-10. https:// doi.org/10.1016/j.amjcard.2014.11.020.
16. Kotseva K, Wood D, De Backer G, De Bacquer D, Pyorala K, Keil U, Euroaspire Study Group. Cardiovascular prevention guidelines in daily practice: a comparison of EUROASPIRE I, II, and III surveys in eight European countries. Lancet. 2009;373(9667):929-40. https://doi.org/10.1016/S01406736(09)60330-5.

17. Frazer K, Callinan JE, McHugh J, van Baarsel S, Clarke A, Doherty K, Kelleher C. Legislative smoking bans for reducing harms from secondhand smoke exposure, smoking prevalence and tobacco consumption. Cochrane Database Syst Rev. 2016;2:CD005992. https://doi.org/10.1002/14651858. CD005992.pub3.

18. World Health Organization. WHO framework convention on tobacco control. Geneva; 2003. Available at [https://www.who.int/fctc/en/]. Accessed 25 February 2020

19. Schmucker J, Wienbergen $H$, Seide S, Fiehn E, Fach A, Wurmann-Busch B, Gohlke H, Gunther K, Ahrens W, Hambrecht R. Smoking ban in public areas is associated with a reduced incidence of hospital admissions due to STelevation myocardial infarctions in non-smokers. Results from the Bremen STEMI registry. Eur J Prev Cardiol. 2014;21(9):1180-6. https://doi.org/10.1177/ 2047487313483610.

20. The Clinical Practice Guideline Treating Tobacco Use and Dependence 2008 Update Panel, Liaisons, and Staff. A clinical practice guideline for treating tobacco use and dependence: 2008 update. A U.S. Public Health Service report. Am J Prev Med. 2008;35(2):158-76. https://doi.org/10.1016/j.amepre. 2008.04.009.

21. West R, McNeill A, Raw M. Smoking cessation guidelines for health professionals: an update. Health Education Authority. Thorax. 2000;55(12): 987-99. https://doi.org/10.1136/thorax.55.12.987.

22. Stead LF, Perera R, Bullen C, Mant D, Lancaster T. Nicotine replacement therapy for smoking cessation. Cochrane Database Syst Rev. 2008; : CD000146. https://doi.org/10.1002/14651858.CD000146.pub3.

23. Balfour D, Benowitz N, Fagerstrom K, Kunze M, Keil U. Diagnosis and treatment of nicotine dependence with emphasis on nicotine replacement therapy. A status report. Eur Heart J. 2000;21(6):438-45. https://doi.org/10. 1053/euhj.1999.1949.

24. Twardella $\mathrm{D}$, Brenner $\mathrm{H}$. Lack of training as a central barrier to the promotion of smoking cessation: a survey among general practitioners in Germany. Eur J Pub Health. 2005;15(2):140-5. https://doi.org/10.1093/ eurpub/cki123.

25. Bruthans J, Mayer O Jr, De Bacquer D, De Smedt D, Reiner Z, Kotseva K, Cifkova R, Euroaspire IV investigators. Educational level and risk profile and risk control in patients with coronary heart disease. Eur J Prev Cardiol. 2016; 23(8):881-90. https://doi.org/10.1177/2047487315601078.

26. Snaterse M, Deckers JW, Lenzen MJ, Jorstad HT, De Bacquer D, Peters RJG, Jennings C, Kotseva K, Scholte Op Reimer WJM, Euroaspire investigators. Smoking cessation in European patients with coronary heart disease. Results from the EUROASPIRE IV survey: a registry from the European society of cardiology. Int J Cardiol. 2018;258:1-6. https://doi.org/10.1016/j.ijcard.2018. 01.064 .

27. Caraballo RS, Kruger J, Asman K, Pederson L, Widome R, Kiefe Cl, Hitsman B, Jacobs DR Jr. Relapse among cigarette smokers: the CARDIA longitudinal study - 1985-2011. Addict Behav. 2014;39(1):101-6. https://doi.org/10.1016/j. addbeh.2013.08.030

28. Hoebel J, Kuntz B, Kroll LE, Finger JD, Zeiher J, Lange C, Lampert T. Trends in absolute and relative educational inequalities in adult smoking since the early 2000s: the case of Germany. Nicotine Tob Res. 2018;20(3):295-302. https://doi.org/10.1093/ntr/ntx087.

29. Xu X, Liu L, Sharma M, Zhao Y. Smoking-related knowledge, attitudes, behaviors, smoking cessation idea and education level among young adult male smokers in Chongqing, China. Int J Environ Res Public Health. 2015; 12(2):2135-49. https://doi.org/10.3390/ijerph120202135.

30. Carney RM, Freedland KE, Miller GE, Jaffe AS. Depression as a risk factor for cardiac mortality and morbidity: a review of potential mechanisms. J Psychosom Res. 2002;53(4):897-902. https://doi.org/10.1016/s00223999(02)00311-2.

31. Freedland KE, Carney RM, Skala JA. Depression and smoking in coronary heart disease. Psychosom Med. 2005;67(Suppl 1):S42-6. https://doi.org/10. 1097/01.psy.0000162255.55629.9c.

32. Goel K, Lennon RJ, Tilbury RT, Squires RW, Thomas RJ. Impact of cardiac rehabilitation on mortality and cardiovascular events after percutaneous coronary intervention in the community. Circulation. 2011;123(21):2344-52. https://doi.org/10.1161/CIRCULATIONAHA.110.983536. 
33. Kotseva K, Wood D, De Backer G, De Bacquer D, Euroaspire III study group Use and effects of cardiac rehabilitation in patients with coronary heart disease: results from the EUROASPIRE III survey. Eur J Prev Cardiol. 2013; 20(5):817-26. https://doi.org/10.1177/2047487312449591.

34. Heran BS, Chen JM, Ebrahim S, Moxham T, Oldridge N, Rees K, Thompson DR, Taylor RS. Exercise-based cardiac rehabilitation for coronary heart disease. Cochrane Database Syst Rev. 2011;7:CD001800. https://doi.org/10. 1002/14651858.CD001800.pub2.

35. Clark AM, Hartling L, Vandermeer B, McAlister FA. Meta-analysis: secondary prevention programs for patients with coronary artery disease. Ann Intern Med. 2005;143(9):659-72. https://doi.org/10.7326/0003-4819-143-9200511010-00010.

36. Taylor RS, Brown A, Ebrahim S, Jolliffe J, Noorani H, Rees K, Skidmore B, Stone JA, Thompson DR, Oldridge N. Exercise-based rehabilitation for patients with coronary heart disease: systematic review and meta-analysis of randomized controlled trials. Am J Med. 2004;1 16(10):682-92. https://doi. org/10.1016/j.amjmed.2004.01.009

37. Anderson L, Thompson DR, Oldridge N, Zwisler AD, Rees K, Martin N, Taylor RS. Exercise-based cardiac rehabilitation for coronary heart disease. Cochrane Database Syst Rev. 2016;1:CD001800. https://doi.org/10.1002/ 14651858.CD001800.pub3.

38. Taylor RS, Unal B, Critchley JA, Capewell S. Mortality reductions in patients receiving exercise-based cardiac rehabilitation: how much can be attributed to cardiovascular risk factor improvements? Eur J Cardiovasc Prev Rehabil. 2006;13(3):369-74. https://doi.org/10.1097/01.hjr.0000199492.00967.11.

39. Kotseva K, Wood D, De Bacquer D, Euroaspire investigators. Determinants of participation and risk factor control according to attendance in cardiac rehabilitation programmes in coronary patients in Europe: EUROASPIRE IV survey. Eur J Prev Cardiol. 2018;25(12):1242-51. https://doi.org/10.1177/ 2047487318781359.

40. Galea S, Tracy M. Participation rates in epidemiologic studies. Ann Epidemiol. 2007;17(9):643-53. https://doi.org/10.1016/j.annepidem.2007.03.013.

41. Patrick DL, Cheadle A, Thompson DC, Diehr P, Koepsell T, Kinne S. The validity of self-reported smoking: a review and meta-analysis. Am J Public Health. 1994;84(7):1086-93. https://doi.org/10.2105/ajph.84.7.1086.

\section{Publisher's Note}

Springer Nature remains neutral with regard to jurisdictional claims in published maps and institutional affiliations.

Ready to submit your research? Choose BMC and benefit from:

- fast, convenient online submission

- thorough peer review by experienced researchers in your field

- rapid publication on acceptance

- support for research data, including large and complex data types

- gold Open Access which fosters wider collaboration and increased citations

- maximum visibility for your research: over $100 \mathrm{M}$ website views per year

At $\mathrm{BMC}$, research is always in progress.

Learn more biomedcentral.com/submissions 